\title{
Quantification of HIV by PCR in monocytes and lymphocytes in patients receiving antiviral treatment and low dose recombinant human granulocyte macrophage colony stimulating factor
}

\author{
F D Davison, R S Kaczmarski, A Pozniak, G J Mufti, S Sutherland
}

\begin{abstract}
Neutropenia induced by antiviral treatment, in particular AZT, can be improved with recombinant human granulocyte macrophage colony stimulating factor (RHGMCSF) in HIV positive patients. However, there has been concern that this may increase the HIV load in the mononuclear cells of such patients. Five patients receiving AZT plus low dose RHGMCSF are reported. There was no consistent change in the levels of HIV DNA in the monocytes and lymphocytes. Additionally, all patients had stable disease with no opportunistic infection during the study period. It is concluded, therefore, that low dose RHGMCSF does not significantly change the viral DNA load in patients receiving AZT.
\end{abstract}

(F Clin Pathol 1994;47:855-857)

An important consequence of HIV infection is the development of peripheral blood cytopenias which can occur in up to $70 \%$ of cases. ${ }^{1}$ The abnormal haemopoiesis brought about by HIV may be aggravated by antiviral treatment as many of these agents, such as AZT (3'azido 2'3'dideoxythymidine), are also myelosuppressive. ${ }^{2}$ Haemopoietic growth factors (HGF), in particular recombinant human granulocyte macrophage colony stimulating factor (RHGMCSF), are now available to treat the cytopenias resulting from HIV infection and AZT treatment. ${ }^{3}$ There have been concerns, however, from in vitro studies of GMCSF that it may increase concentrations of intracellular HIV in monocytes/macrophages by upregulating, directly or via other cytokines, HIV transcription through the proviral long terminal receptors ${ }^{4}$ Furthermore, GMCSF may contribute to an overall increase in the viral load by increasing the total number of monocytes/macrophages. However, other in vitro studies have shown that monocytes/macrophages exposed to GMCSF showed an enhanced susceptibility to AZT as a result of increased intracellular concentrations of thymidine kinase and phosphorylation of AZT to its active metabolites. ${ }^{5}$ In this study we examined sequential blood samples from HIV positive patients receiving $A Z T$ and low dose RHGMCSF. PCR quantification techniques were used to assess the amount of leucocyte HIV DNA and RNA in each sample during treatment. The presence of DNA represents a total of integrated provirus and extrachromosomal HIV DNA which is typically present in the cells of HIV positive subjects. Intracellular RNA is indicative of replication and unpackaged virions.

\section{Methods}

Five patients were treated with RHGMCSF as part of a pilot study of low dose treatment. Patients with neutropenia related to HIV or AZT treatment received RHGMCSF at between $5-20 \mathrm{mcg} / \mathrm{m}^{2}$; the dose was adjusted to keep the absolute neutrophil count above $1.5 \times 10 \%$. AZT was given concurrently at 500-600 mg/day. Patients' clinical details, baseline absolute neutrophil count, CD4 + counts, p24 antigen and AZT doses are shown in the table. All patients had stable disease, with no active opportunistic infections throughout the study period.

Blood samples were taken before RHGMCSF treatment and at monthly intervals thereafter for three or four months. Mononuclear cells were isolated by FicollHypaque (Pharmacia) density gradient centrifugation. Monocytes/macrophages were enriched by plastic adherence and supernatant lymphocytes collected for DNA analysis. Adherent monocytes/macrophages cells were $T$ cell depleted using anti-CD2 coated immunomagnetic beads (Dynal), then counted, pelleted, and stored at $-70^{\circ} \mathrm{C}$ pending DNA analysis. FACS analysis for CD3 showed less than $2 \%$ contaminating $\mathrm{T}$ cells.

Viral antigen (p24) concentrations were
Haematology Department, King's College Hospital, London

R S Kaczmarski

G J Mufti

Department of Genitourinary Medicine, King's College Hospital, London

A Pozniak

Correspondence to: Dr S Sutherland

Accepted for publication 24 March 1994
Clinical and haematological data of study patients at entry

\begin{tabular}{|c|c|c|c|c|c|c|c|c|c|}
\hline $\begin{array}{l}\text { Case } \\
\text { No }\end{array}$ & $\begin{array}{l}\text { Age/ } \\
\text { sex }\end{array}$ & $\begin{array}{l}\text { Risk } \\
\text { group }\end{array}$ & $\begin{array}{l}C D C \\
\text { group }\end{array}$ & $\begin{array}{l}\text { ANC before } \\
G M-C S F \\
\left(\times 10^{9} / l\right)\end{array}$ & $\begin{array}{l}\text { Dose of } \\
G M-C S F \\
\left(m c g / m^{2} / d a y\right)\end{array}$ & $\begin{array}{l}A N C \text { after } \\
G M-C S F \\
\left(\times 10^{\circ} / l\right)\end{array}$ & $\begin{array}{l}C D 4+ \\
\left(\times 10^{6} / l\right)\end{array}$ & $\begin{array}{l}A Z T \\
m g / d a y\end{array}$ & $\begin{array}{l}\text { Treatment } \\
\text { duration } \\
\text { (weeks) }\end{array}$ \\
\hline $\begin{array}{l}1 \\
2 \\
3 \\
4 \\
5\end{array}$ & $\begin{array}{l}41 / M \\
31 / F \\
28 / M \\
26 / M \\
32 / M\end{array}$ & $\begin{array}{l}\text { Homosexual } \\
\text { African } \\
\text { Homosexual } \\
\text { Homosexual } \\
\text { Homosexual }\end{array}$ & $\begin{array}{l}\text { IV } \\
\text { III } \\
\text { III } \\
\text { III } \\
\text { IV }\end{array}$ & $\begin{array}{l}0.8 \\
0.6 \\
0.9 \\
0.6 \\
0.7\end{array}$ & $\begin{array}{r}5 \\
5 \\
5 \\
5 \\
10\end{array}$ & $\begin{array}{l}1 \cdot 9 \\
4 \cdot 0 \\
2 \cdot 1 \\
2 \cdot 9 \\
3 \cdot 8\end{array}$ & $\begin{array}{l}<25 \\
230 \\
<25 \\
<25 \\
<25\end{array}$ & $\begin{array}{l}500 \\
600 \\
500 \\
600 \\
600^{\star}\end{array}$ & $\begin{array}{l}12 \\
14 \\
10 \\
12 \\
16\end{array}$ \\
\hline
\end{tabular}

*Also receiving dideoxyinosine (ddI), $600 \mathrm{mg} /$ day. 
Figure 1 The concentrations of HIV DNA at each monthly interval are shown for monocytes $(A)$ and lymphocytes $(B)$ in all patients. Lymphocyte counts were not available for case 5.
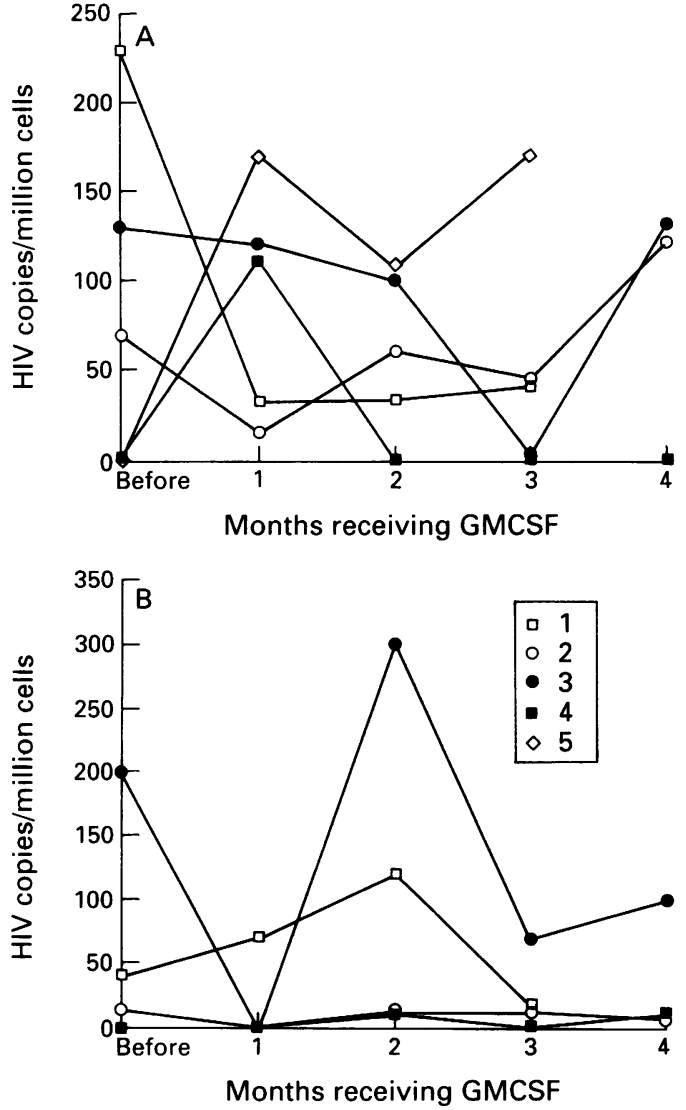

determined on serial serum/plasma samples using the HIVAG-1 kit (Abbott) both with and without prior acid dissociation of antigen and antibody. Cytokine assays for TNF- $\alpha$, IFN- $\gamma$, IL-6, and IL-1B were done on these samples using sensitive enzyme linked immunoabsorbent assays (ELISAs).

Nucleic acids were prepared from monocytes/macrophages for viral PCR and lymphocytes by guanidium-phenol purification. ${ }^{6}$ DNA from $25 \%$ of the cells in each sample was used for DNA analysis and the remainder for RNA. For HIV DNA PCR, the primers were SK 68/69 amplifying a 134 base pair fragment of the $e n v$ gene. ${ }^{7}$ Primers for RNA were pol $1 / 2$, amplifying a 143 base pair fragment. ${ }^{8}$ The monthly samples from each patient were analysed together as a batch so as to minimise any experimental variation between them. Serial dilutions of cloned HIV DNA were amplified in parallel with samples to permit quantification within a range of about 20-2500 copies. The PCR cycle conditions were $94^{\circ} \mathrm{C}$ for one minute, then $61^{\circ} \mathrm{C}$ for two minutes for a total of 32 cycles, followed by a five minute extension at $72^{\circ} \mathrm{C}$ with the reaction still remaining in the exponential phase which is necessary for quantification. One env primer was end-labelled by polynucleotide kinase with $\mathrm{P}^{32}$ to enhance sensitivity and to enable the amplified product to be quantified. After PCR, $10 \mu \mathrm{l}$ aliquots of each reaction, including the standards, were electrophoresed in agarose gel which was then dried and autoradiographed for several hours or overnight. The amplified products were excised from the dried gel and counted by scintillation counting. The ampli- fied standards were used to plot the HIV copy number against counts, and from this curve the number of HIV copies in each test sample was extrapolated. The copy number was expressed relative to the number of cells in each sample of monocytes/macrophages and lymphocytes from which DNA was extracted. To ascertain the intra-assay reproducibility, a single HIV positive sample from a patient with a low HIV p24 antigen titre was amplified 10 times in the same run.

RNA was treated with DNAse 1 and aliquots of some samples were checked on agarose gels to confirm their integrity. cDNA was generated using random hexamers and AMV reverse transcriptase (Promega) in a $10 \mu \mathrm{l}$ reaction. The complete reaction volume was amplified by PCR using pol gene primers under the same conditions as in DNA above. Lymphocyte RNA preparations were run with and without reverse transcriptase to exclude false positive results.

\section{Results}

The assessment of intra-assay reproducibility for HIV DNA using a single HIV positive sample repeated 10 times produced a standard deviation of $17 \%$ from the initial mean value (data not shown).

When considering samples from all patients, the HIV DNA copy number per $10^{6}$ cells ranged from two to 230 in the monocytes/macrophages and from 17 to 300 in the lymphocytes. In any individual patient maximum variation between samples in copy number per $10^{6}$ cells was from two to 130 for monocytes/macrophages and from 17 to 120 in the lymphocytes. In two patients there was a sharp but unsustained increase in monocyte HIV DNA in the first month after treatment; in another patient there was a sustained decrease, while in two others, the amounts remained largely unchanged (fig 1). In any one patient the variation appeared random, particularly in lymphocytes, where there was no trend in the fluctuations of HIV copies during the course of treatment. An autoradiograph of HIV DNA PCR products from case 2 with standards is shown in fig 2 .

Cellular HIV RNA analysis by PCR was done on four patients because degradation of material was observed in the fifth patient. RNA was detectable in the monocytes of one patient and in the lymphocytes of all patients, but not in every sample. The RNA concentrations were all low, in the order of one copy per $10^{6}$ cells and the strength of the signal reflected the number of cells in that sample. There was no obvious trend in RNA concentrations with time.

Cytokine measurements showed low or unrecordable concentrations of TNF- $\alpha$ and IL-6. Concentrations of IL- $1 \alpha$ rose from 0 to $883 \mathrm{pg} / \mathrm{ml}$ in case 3, fell from 383 to $0 \mathrm{pg} / \mathrm{ml}$ in case 5 , and remained unchanged in three other patients. Concentrations of IFN- $\gamma$ were undetectable in all except case 3 in whom this rose from 40 to $60 \mathrm{pg} / \mathrm{ml}$ during the course of treatment. p24 antigen was detected only in 
Figure 2 Representative autoradiograph of $P C R$ products from case 2 . Lanes 1-5 and 6-10 show amplified HIV DNA from monthly leucocyte samples during RHGMCSF treatment; the first lane is before treatment. Lanes $11-15$ are cloned standards of HIV DNA: 0, 20, 100, 500, 2500 copies,

respectively. The amplified HIV DNA fragment (139 base pairs) is arrowed.
Lymphocytes

Monocytes Standards

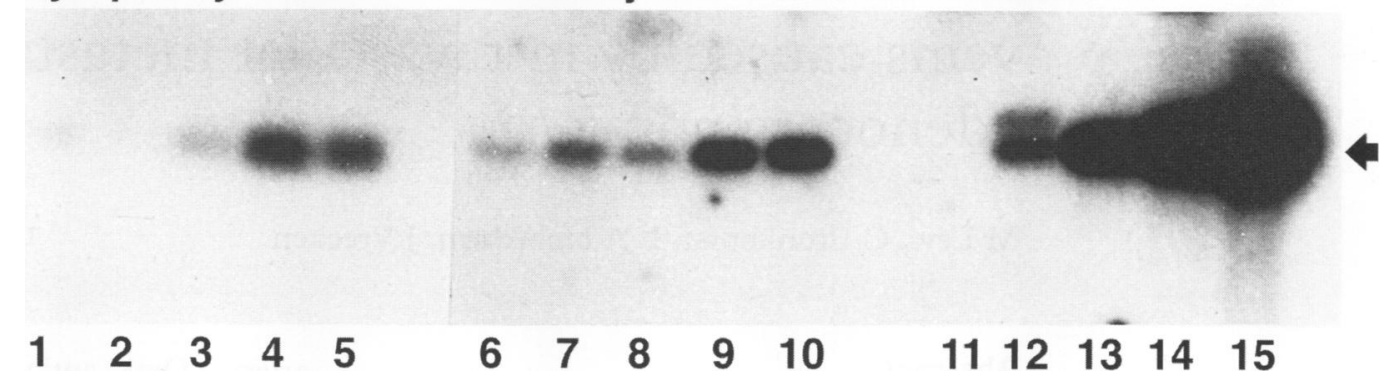

case 5: the concentration fell from $250 \mathrm{pg} / \mathrm{ml}$ before treatment to $27 \mathrm{pg} / \mathrm{ml}$ at the end of the study. All patients had low values of p24 antigen after acid dissociation but this did not increase in any of them during treatment.

\section{Discussion}

Theoretical considerations indicated that in the presence of RHGMCSF, intracellular concentrations of HIV in monocytes/ macrophages could either increase, due to upregulation of HIV replication and the increased turnover of host cells, or decrease as a consequence of enhancement of the effects of AZT on these cells. ${ }^{45}$

The results from these five patients suggest that low dose RHGMCSF does not appreciably alter concentrations of HIV DNA in the circulating monocytes/macrophages or lymphocytes. These DNA concentrations are likely to be a reflection of random changes in viral turnover which may in turn be a consequence of changes in the activation state of the host cell. The main effect of RHGMCSF on cellular transcription enhancers such as NF-KB, is likely to be indirect and mediated by other cytokines, such as TNF- $\alpha$ and IL- 6 . Increased concentrations of these cytokines have been reported in HIV positive patients, and are thought to be a consequence of the antigenaemia, opportunistic, and other intercurrent infections. However, we found low or undetectable concentrations of TNF- $\alpha$ and IL-6 in this group of patients. Side effects of RHGMCSF treatment include fever, flu-like symptoms, bone pain and hypoalbuminaemia and cachexia with prolonged administration at conventionally used doses of 3-10 $\mathrm{mcg} / \mathrm{kg} / \mathrm{day}$; these side effects may be related to the induction of other cytokines. As low dose RHGMCSF was well tolerated with no systemic side effects and there was no change in the concentrations of IL- $1, \mathrm{TNF} \alpha$, and IL6 , this suggests that low dose RHGMCSF treatment does not induce these cytokines and that it is both safe and effective in increasing the neutrophil counts. Furthermore, all patients had stable disease with no intercurrent illnesses during the study period.

The concentrations of HIV DNA that we observed were likely to reflect the amount of mature virus produced from an infected cell, but the precise association between integrated provirus and mature virion production is still unclear. Other studies have shown that the life cycle of HIV is significantly different in cells of monocytic origin where higher con-
HIV DNA are found. It has been suggested that these forms may also be transcriptionally active. ${ }^{9}$ It is not clear whether intracellular concentrations of AZT significantly change the number of copies of HIV proviral DNA. The low concentrations of intracellular RNA detected suggest that there was little virion production in circulating blood mononuclear cells. However, it may reflect inefficiency of the reverse transcriptase reaction or some RNA degradation due to its labile nature. The problems associated with quantifying HIV RNA after reverse transcription and PCR were discussed by Semple et al, ${ }^{8}$ in particular the low efficiency of reverse transcription (around 5\%). When RNA is at such low levels, meaningful quantification is difficult. It should be noted that the prevalence of mononuclear cells expressing HIV RNA is typically 100-fold lower than those harbouring DNA. ${ }^{10}$

Although at this point only a relatively small number of patients have been studied, low dose RHGMCSF treatment does not seem to alter substantially the viral DNA load in peripheral blood monocytes or lymphocytes in patients receiving AZT.

1 Scadden DT, Zon LI, Groopman JE. Pathophysiology and management of HIV-associated hematologic disorders. Blood 1989;74:1455-63.

2 Groopman JE, Mitsuyasu RT, DeLo MJ, Oette DH, Golde DW. Effect of recombinant human granulocytemacrophage colony stimulating factor on myelopoiesis in the acquired immunodeficiency syndrome. $N$ Engl $\mathcal{F}$ Med 1987;317:593.

3 Duh EJ, Maury WJ, Folks TM, Fauci AS, Robson AB. Tumor necrosis factor alpha activates human immunodeficiency virus type 1 through induction of nuclear factor binding to the NF-Kappa B sites in the long tor binding to the NF-Kappa B sites in the long
terminal repeat. Proc Natl Acad Sci USA 1989;86: terminal

4 Koynangi Y, O'Brien WA, Zhao JQ, Golde DW, Gasson $\mathrm{J}$, Chen ISY. Cytokines alter production of HIV-1 from primary mononuclear phagocytes. Science 1988;241 1673-5.

5 Perno CF, Yarchoan R, Cooney DA, Hartman NR Webb DSA, Hao Z, et al. Replication of human macrophage colony stimulating factor (GM-CSF) macrophage colony stimulating factor (GM-CSF) potentiates viral production yet enhances the antivira effect mediated by 3'-Azidothymidine-2'3'-dideoxythymidine (AZT) and other dideoxynucleoside cogeners of thymidine. F Exp Med 1989;169:933-51.

Chomczynski P, Saachi N. Single-step method of RNA isolation by acid guanidium thiocyanate-phenol-chloro-

7 Ou C-Y, Kwok S, Mitchell SW, Mauk DH, Sninsky J, Krebs JW, et al. DNA amplification for direct detection of HIV-1 in DNA of peripheral blood mononuclea cells. Science 1988;239:295-7.

8 Semple MG, Kaye S, Loveday C, Tedder R. HIV-1 plasma viraemia quantification: a non-culture measurement needed for therapeutic trials. I Virol Methods 1992;41:167-80.

$9 \mathrm{Li} \mathrm{Y,} \mathrm{Kappes} \mathrm{JC,} \mathrm{Conway} \mathrm{JA,} \mathrm{Price} \mathrm{RW,} \mathrm{Shaw} \mathrm{GM}$ Hahn B. Molecular characterisation of HIV-1 cloned Identification of replication-competent and -defective genomes. $₹$ Virol 1991;65:3973-85.

10 Stevenson M, Stanwick TL, Dempsey MP, Lamonica CA. HIV-1 replication is controlled at the level of T cell immunodeficiency virus in monocytes; granulocyteform extraction. Analyt Biochem 1987;162:157-9. directly from uncultured human brain tissue: 